\title{
Novel therapies are changing treatment paradigms in metastatic prostate cancer
}

\author{
Eric Powers' ${ }^{1}$, Georgia Sofia Karachaliou ${ }^{2,3}$, Chester Kao ${ }^{1}$, Michael R. Harrison ${ }^{2,3}$, Christopher J. Hoimes ${ }^{2,3}$, \\ Daniel J. George ${ }^{2,3}$, Andrew J. Armstrong ${ }^{2,3,4}$ and Tian Zhang ${ }^{2,3^{*}}$ (]
}

\begin{abstract} and the promising agents currently in ongoing clinical trials.

\section{Introduction}

Prostate cancer (PC) is the second most commonly diagnosed cancer among men worldwide, following lung cancer, and the first among men in the USA [1]. Although clinical outcomes are excellent for patients with localized disease, patients with metastatic prostate cancer ( $\mathrm{mPC}$ ) have poor prognosis, with a 5-year survival rate reaching $30 \%$. Androgen deprivation therapy (ADT) has long been the treatment of choice as backbone of all other therapies, by reducing circulating androgens to castration levels and slowing the progression of the disease. Unfortunately, ADT as a single agent does not always prevent disease progression, and eventually hormone-sensitive prostate cancer (HSPC) will develop resistance even at low testosterone levels and become castration-resistant prostate cancer (CRPC).
\end{abstract}

Metastatic castration-resistant prostate cancer (MCRPC) remains a terminal diagnosis with an aggressive disease course despite currently approved therapeutics. The recent successful development of poly ADP-ribose polymerase (PARP) inhibitors for patients with $\mathrm{MCRPC}$ and mutations in DNA damage repair genes has added to the treatment armamentarium and improved personalized treatments for prostate cancer. Other promising therapeutic agents currently in clinical development include the radiotherapeutic 177-lutetium-prostate-specific membrane antigen (PSMA)-617 targeting PSMA-expressing prostate cancer and combinations of immunotherapy with currently effective treatment options for prostate cancer. Herein, we have highlighted the progress in systemic treatments for mCRPC

Keywords: Metastatic prostate cancer, Castration-resistant prostate cancer, Prostate-specific membrane antigen (PSMA), Polyadenosine diphosphate [ADP]-ribose polymerase (PARP) inhibitor, Androgen receptor inhibitors (ARIs)

*Correspondence: tian.zhang2@duke.edu

2 Division of Medical Oncology, Department of Medicine, Duke University, DUMC 103861, Durham, NC 27710, USA

Full list of author information is available at the end of the article
Over the last few years, several successful phase-3 trials have expanded the available treatments in metastatic HSPC with docetaxel (CHAARTED, GETUG-AFU 15, and STAMPEDE $[2,3]$ ), abiraterone acetate (STAMPEDE and LATITUDE), enzalutamide (ARCHES, ENZAMET $[4,5]$ ), and apalutamide (TITAN [6]). In addition, current standard therapy for patients with CRPC apart from ADT includes sipuleucel-T, chemotherapy (docetaxel if no prior use, or cabazitaxel if prior docetaxel), abiraterone acetate, enzalutamide, olaparib and rucaparib (for molecularly selected patients with mutations in DNA damage repair genes), and radium-223 (for bone metastases). However, mCRPC remains a lethal diagnosis, and more effective therapeutic approaches against mCRPC are necessary to further improve clinical outcomes.

While progress is ongoing for many new targeted treatments in $\mathrm{mCRPC}$, we will highlight here the clinical progress of the recently US FDA-approved poly ADP-ribose polymerase (PARP) inhibitors, new indications for the second-generation androgen receptor antagonists, and original author(s) and the source, provide a link to the Creative Commons licence, and indicate if changes were made. The images or other third party material in this article are included in the article's Creative Commons licence, unless indicated otherwise in a credit line to the material. If material is not included in the article's Creative Commons licence and your intended use is not permitted by statutory regulation or exceeds the permitted use, you will need to obtain permission directly from the copyright holder. To view a copy of this licence, visit http://creativecommons.org/licenses/by/4.0/. The Creative Commons Public Domain Dedication waiver (http://creativeco mmons.org/publicdomain/zero/1.0/) applies to the data made available in this article, unless otherwise stated in a credit line to the data. 
promising radiopharmaceutical and immunotherapy agents.

\section{Main text \\ PARP inhibitors}

Polyadenosine diphosphate [ADP]-ribose polymerase (PARP) is a nuclear enzyme that aids the repair of singlestrand DNA breaks (SSBs) [7-9]. Cells with an intact repair apparatus have two major mechanisms for repairing double-strand breaks (DSBs), including homologous recombination repair (HRR) and non-homologous endjoining (NHEJ). Cells with mutations in the HRR machinery, such as those with mutations in BRCA1, BRCA2, and $A T M$, are forced toward the more error-prone DSB repair pathway of NHEJ, leading to genomic instability and cellular death. Based on this concept, the first application of PARP inhibitors was in patients with ovarian cancer; patients with $B R C A 1 / 2$ and other HRR mutations achieved longer progression-free survival (PFS) benefits [10-12].

In mCRPC, PARP inhibitors were first applied in those patients who harbored $B R C A 1 / 2$ mutations and had already progressed on previous treatments [13]. In a phase-2 clinical study, 49 patients with mCRPC were treated with olaparib. Sixteen out of these 49 patients had somatic or germline mutations in DNA repair genes. Eighty-eight percent (14/16) of patients with DNA repair gene mutations reached significantly longer PFS (9.8 vs. 2.7 months) and overall survival (OS, 13.8 vs. 7.5 months) compared to those patients without these mutations [14]. In a subsequent phase- 2 study of 92 patients with DNA repair gene aberrations, patients were randomized to olaparib at either $300 \mathrm{mg}$ or $400 \mathrm{mg}$ twice daily. Of the 46 patients treated with $400 \mathrm{mg}$, 25 patients (54\%) had an objective response (OR) and 18/46 (39\%) patients in the $300 \mathrm{mg}$ group had objective responses [15].

Recently published data from the open-label phase-3 PROfound trial (NCT02987543) confirmed the efficacy of olaparib in patients with mCRPC. Three hundred and eighty-seven patients with $\mathrm{MCRPC}$ progressing on prior abiraterone or enzalutamide were randomized 2:1 to receive either olaparib $300 \mathrm{mg}$ twice daily or investigator's choice of enzalutamide or abiraterone acetate. Patients were divided into two cohorts based on their HRR gene mutation. Patients with mutations in $B R C A 1, B R C A 2$, or $A T M$ were randomized in cohort $\mathrm{A}$ $(N=245)$, and patients with mutations among 12 other genes involved in the HRR pathway were randomized in cohort B $(N=142)$. In patients with at least one alteration in BRCA1/2 or ATM (cohort A), olaparib prolonged radiographic PFS (rPFS) from 3.6 to 7.4 months $(\mathrm{HR}=0.34 ; 95 \%$ CI $0.25-0.47 ; p$ value $<0.001)$, and improved median OS from 15.1 months (control cohort) to 18.5 months (olaparib-treated cohort) $(\mathrm{HR}=0.64,95 \%$ CI $0.43-0.97, p=0.02)$ [16]. In addition, the confirmed objective response rate (ORR) was $33 \%$ (28/84 patients) in the olaparib group and $2 \%(1 / 43$ patients) in the control group (OR 20.86, 95\% CI 4.18$379.18, p<0.001)$. Fifty percentage of prostate-specific antigen (PSA) decline responses was confirmed in $43 \%(66 / 153)$ of patients in the olaparib group and $8 \%$ $(6 / 77)$ in the control group. The observed efficacy not only in cohort A but also in the overall population was seen regardless of whether olaparib monotherapy was administered before or after chemotherapy. The most common grade 3 and higher adverse events from olaparib included anemia (21\%), fatigue (3\%), nausea/vomiting, dyspnea, and urinary tract infections ( $2 \%$ each) [16]. When evaluating subsets of patients with different HRR mutations, patients with BRCA2 mutations tended to achieve better responses and longer rPFS than patients who had BRCA1 or ATM mutations.

Based on these results, olaparib was fully approved by the US FDA in May 2020 for patients with mCRPC who have deleterious or suspected deleterious germline or somatic HRR gene mutations and whose cancer has progressed with abiraterone or enzalutamide. However, given that olaparib was not compared against chemotherapy, patient selection for olaparib should depend upon the mutation and whether a standard treatment (such as chemotherapy) might be an available, potentially more active treatment.

In a similar approach, the TRITON2 study led to an accelerated FDA approval of rucaparib $600 \mathrm{mg}$ twice daily for patients with mCRPC, BRCA1/2 mutations and prior progression from both androgen receptordirected treatment and taxane-based chemotherapy. The TRITON2 (NCT02952534) study was a multicenter, single-arm trial of 190 patients with $B R C A 1 / 2$, $A T M$ or other prespecified $D D R$-mutated mCRPC who had disease progression on prior androgen receptor-directed therapy and taxane-based chemotherapy [17]. Among patients with a $B R C A 1 / 2$ alteration and measurable disease at baseline, the ORR was 43.9\% (95\% CI 30.7-57.6). Moreover, 59.6\% (34/57) of patients achieved a confirmed PSA response $(\geq 50 \%)$ (95\% CI 45.8-72.4), and the median duration of PSA response was 6.5 months (95\% CI 5.7-7.5). The most common any grade adverse events (AEs) in rucaparibtreated patients included asthenia/fatigue (55.3\%), nausea (49.5\%), anemia (37.9\%), and decreased appetite (27.9\%). The confirmatory phase-3 TRITON3 trial continues to enroll and randomize patients with mCRPC and mutations in BRCA1/2 or $A T M$ to rucaparib versus physician's choice of therapy (NCT02975934). 
Early evidence regarding combinations of PARP inhibitors with standard MCRPC therapies

There is conflicting evidence supporting the use of PARP inhibitors in mCRPC patients without mutations in DNA repair genes. The potential utility of PARP inhibitors in this setting will likely only be in combination with another effective agent. Preclinical studies have shown that inhibiting the androgen pathway can induce cell sensitivity to PARP inhibition, suggesting a synergy between androgen pathway blockade and PARP inhibitors-forming the hypothesis of multiple clinical trials [18-20]. Ongoing phase $2 / 3$ controlled clinical trials investigating PARP inhibitors in $\mathrm{mCRPC}$ with or without the concurrent administration of another agent have been summarized (Table 1 ).

A phase-2 randomized trial of 142 patients comparing olaparib with abiraterone acetate to placebo with abiraterone acetate found a significant difference in rPFS (13.8 vs. 8.2 months, respectively, $p=0.034$ ) [19]. The presence of DNA damage repair gene alterations was not an inclusion criterion, although a prespecified subgroup analysis of those patients with pertinent mutations (21/142) found no difference in PFS between the treatment cohorts, though the small numbers limited the subset's power to detect a difference. A separate phase-2 trial of 148 patients compared veliparib plus abiraterone acetate to abiraterone acetate alone and found no difference in either PSA reduction or radiologic response, although secondary analysis showed a signal for improved outcomes in the small subgroup of patients with DNA repair defects [20]. The difference in these two trials may be explained by the reduced potency of veliparib compared to olaparib to trap PARP on single-strand breaks [21]. The phase-3 PROpel trial (NCT03732820) investigating olaparib plus abiraterone acetate in patients who have not yet received chemotherapy or anti-androgen therapy has completed enrollment and will provide further clarity on this issue. In addition to anti-androgen agents, combinations of PARP inhibitors with other treatments for prostate cancer (such as anti-angiogenic, radioligand, and immunotherapy) are being investigated in ongoing trials [22].

\section{Novel androgen receptor inhibitors: new indications in non-metastatic CRPC}

Androgen receptor (AR) signaling remains an important driver of tumor growth even in CRPC [23]. Second-generation AR antagonists such as enzalutamide have become standard of care for CRPC [24]. These agents have greater affinity and no agonist activity to the AR binding domain, thereby blocking the nuclear translocation of AR and decreasing downstream androgen-dependent genes [25]. Enzalutamide significantly improved OS and PFS in $\mathrm{mCRPC}$ compared to placebo in phase- 3 trials, both in the chemotherapy-pretreated

Table 1 Ongoing phase 2/3 controlled trials investigating PARP inhibitors in mCRPC

\begin{tabular}{|c|c|c|c|c|c|c|c|}
\hline Trial name & Intervention & Control & $\begin{array}{l}\text { DNA repair } \\
\text { mutation } \\
\text { required }\end{array}$ & $\begin{array}{l}\text { Prior treatment } \\
\text { for } \mathrm{mCRPC} \\
\text { allowed }\end{array}$ & $\begin{array}{l}\text { Estimated } \\
\text { enrollment } \\
\text { (patients) }\end{array}$ & Trial phase & $\begin{array}{l}\text { Clinicaltrials. } \\
\text { gov } \\
\text { identifier }\end{array}$ \\
\hline BRCAAway & $\begin{array}{l}\text { Olaparib or olaparib/ } \\
\text { AAP }\end{array}$ & AAP & Yes & No & 70 & 2 & NCT03012321 \\
\hline PROpel & Olaparib/AAP & AAP & No & No & 720 & 3 & NCT03732820 \\
\hline COMRADE & Olaparib/Ra 223 & Ra 223 & No & Yes & 112 & $1 / 2$ & NCT03317392 \\
\hline KEYLYNK-010 & $\begin{array}{l}\text { Olaparib/pembroli- } \\
\text { zumab }\end{array}$ & AAP or enzalutamide & No & Yes & 780 & 3 & NCT03834519 \\
\hline KEYNOTE-365 & $\begin{array}{l}\text { Olaparib/pembroli- } \\
\text { zumab }\end{array}$ & $\begin{array}{l}\text { Pembroli- } \\
\text { zumab + one of } \\
\text { docetaxel, enzalu- } \\
\text { tamide, or AAP }\end{array}$ & No & Yes & 400 & $1 \mathrm{~b} / 2$ & NCT02861573 \\
\hline TRITON3 & Rucaparib & $\begin{array}{l}\text { AAP or enzalutamide } \\
\text { or docetaxel }\end{array}$ & Yes & No & 400 & 3 & NCT02975934 \\
\hline $\mathrm{N} / \mathrm{A}$ & $\begin{array}{l}\text { Rucaparib or ruca- } \\
\text { parib/nivolumab }\end{array}$ & Nivolumab & No & No & 60 & $1 b / 2$ & NCT03572478 \\
\hline CheckMate 9KD & Rucaparib/nivolumab & $\begin{array}{l}\text { Nivolumab + enza- } \\
\text { lutamide or } \\
\text { docetaxel }\end{array}$ & No & Yes & 330 & 2 & NCT03338790 \\
\hline MAGNITUDE & Niraparib/AAP & AAP & No & No & 1000 & 3 & NCT03748641 \\
\hline TALAPRO-2 & $\begin{array}{l}\text { Talazoparib/enzalu- } \\
\text { tamide }\end{array}$ & Enzalutamide & No & No & 1037 & 3 & NCT03395197 \\
\hline
\end{tabular}


(AFFIRM [26]) and in the chemotherapy-naïve settings (PREVAIL [27]).

For patients with non-metastatic CRPC (nmCRPC), recent data from the double-blinded, phase-3 PROSPER trial showed that administration of enzalutamide plus ADT prolonged median OS to 67.0 months compared to 56.3 months for the placebo plus ADT group (HR 0.73, 95\% CI 0.61-0.89; $p=0.001)$. Fatigue and musculoskeletal events were the most frequent adverse events [28].

In addition, apalutamide and darolutamide have both gained US FDA approval in nmCRPC, based on phase- 3 trials showing prolongation of metastasis-free survival (MFS). In the SPARTAN study of apalutamide versus placebo, MFS was prolonged by two years in the apalutamide cohort (40.5 vs. 16.2 months), while median OS was not yet reached in the apalutamide cohort versus 39 months in the placebo cohort $[29,30]$.

In the phase-3 ARAMIS trial, 1509 patients with nmCRPC were randomized to ADT plus either darolutamide or placebo [31]. The final analysis showed a statistically significant OS benefit corresponding to a $31 \%$ reduction in the risk of death in the treatment cohort (HR 0.69, 95\% CI 0.53-0.88, $p=0.003$ ) [32]. Regarding the most common AEs of darolutamide (any grade), only fatigue $(12.1 \%$ vs. $8.7 \%)$, back pain $(8.8 \%$ vs. $9.0 \%)$, arthralgia ( $8.1 \%$ vs. $9.2 \%)$, and hypertension $(6.6 \%$ vs. $5.2 \%)$ were different between the two groups. There were no differences in seizures ( $0.2 \%$ for both groups), fractures $(4.2 \%$ vs. $3.6 \%)$, or falls $(4.2 \%$ vs. $4.7 \%)$ noted between the two groups.

It is clear that these agents provide statistically significant and clinically meaningful benefit in the treatment of nmCRPC. Darolutamide appears to have a lower rate of AEs [33]. Given its favorable toxicity profile, darolutamide may emerge as the agent of choice for patients who are on neuroactive medications or otherwise at increased risk for neurologic AEs. The ongoing phase-2 trials ODENZA and ARACOG comparing darolutamide and enzalutamide in MCRPC will address outcomes of patient preference and cognitive function, respectively (NCT03314324, NCT04335682). Although the OS data from PROSPER, SPARTAN, and ARAMIS are not mature (longer follow-up is required), studies have found a strong association of MFS with OS, as well as quality-oflife measures and PSA progression, making MFS a clinically important surrogate endpoint [34, 35], leading to the approval of these three AR antagonists in nmCRPC.

A novel treatment targeting degradation of the androgen receptor has emerged as an alternative potential therapeutic approach in patients with mCRPC. In particular, proteolysis-targeting chimeras (PROTACs) are heterobifunctional molecules that work by creating a trimeric complex between a target protein and an E3 ubiquitin ligase, facilitating target ubiquitination and subsequent degradation [36, 37]. Recently published data suggested that ARCC-4, a low-nanomolar AR degrader, is able to degrade about $95 \%$ of cellular AR [37]. Moreover, ARCC-4 inhibits prostate tumor cell proliferation even in high androgen environments and degrades clinically relevant AR with point mutations resistant to enzalutamide, addressing enzalutamide-resistant hurdles [37, 38]. Additionally, in enzalutamide-resistant model systems, administration of another AR degrader, ARD-61, in vitro and in vivo results has shown more potent antiproliferative, pro-apoptotic effects [39]. The first phase-1 trial of ARV-110, an orally bioavailable PROTAC, in 18 patients with $\mathrm{mCRPC}$, showed that two patients achieved confirmed $\geq 50 \%$ PSA reduction (both treated with ARV110 at $140 \mathrm{mg}$ once daily). There were two patients who developed grade 3/4 elevated AST/ALT levels but no other observed grade 3 or 4 treatment-related AEs [40].

While the second-generation AR inhibitors now have an expanded role in nmCRPC, ongoing clinical development of AR degraders and other novel therapies may expand treatment options in the future. In addition, it should be noted that these AR inhibitors all bind AR in the testosterone-binding domain, and therefore, resistance mechanisms may be similar and the agents likely would not have further efficacy if used as sequential monotherapies.

\section{Radiopharmaceuticals}

Radiopharmaceutical agents allow systemic delivery of radiotherapy. In prostate cancer, phosphorus-32, strontium-89, and samarium-153 have been studied but did not show a survival benefit [41, 42]. Phosphorus-32 $\left({ }^{32} \mathrm{P}\right)$, a $\beta$-emitter, the first US FDA-approved radiopharmaceutical in 1952, localizes to remodeling areas in bone including osteoblastic lesions and can relieve cancer-related bone pain [43-45]. Strontium-89 $\left({ }^{89} \mathrm{Sr}\right)$, a $\beta$-particle emitter that functions in vivo as a calcium analog, was FDA-approved for management of bone metastatic CRPC in 1993; a phase-3 trial in bone metastatic CRPC demonstrated improvement in palliation of bone pain but with no survival benefit $[44,46]$. Samarium-153 $\left({ }^{153} \mathrm{Sm}\right)$, a $\beta$ - and $\gamma$-emitter, was FDA-approved in 1997 as a chelate with ethylenediaminetetramethylenephosphonic acid (Sm-EDTMP or ${ }^{153} \mathrm{Sm}$ lexidronam), which interacts with hydroxyapatite of bone in regions of osteoblastic lesions; the FDA approval was based on phase-3 studies demonstrating pain palliation, but no survival benefit was detected $[44,45,47,48]$.

Radium-223 is currently the only radiopharmaceutical treatment for mCRPC that improved overall survival for patients with mCRPC and symptomatic bone metastatic disease [49-51]. More recently, two other radioisotopes, 
lutetium-177 $\left({ }^{177} \mathrm{Lu}\right)$ and gallium-68 $\left({ }^{68} \mathrm{Ga}\right)$, are being developed for patients with mCRPC and targeted to the cell surface molecule, prostate-specific membrane antigen (PSMA). While ${ }^{68} \mathrm{Ga}$ is mainly being developed as an imaging agent in positron emission tomography (PET) scans, ${ }^{177} \mathrm{Lu}$ is the main therapeutic radioisotope and will be the focus of discussion here.

\section{7-Lutetium-PSMA-617}

${ }^{177}$ Lutetium $\left({ }^{177} \mathrm{Lu}\right)$ is a beta-emitting, medium-energy radioisotope that is ideally suited for use in MCRPC due to its desirable physical properties: (1) the maximum energy $\beta$-emission of $0.5 \mathrm{meV}$ with short penetration range of around $0.67 \mathrm{~mm}$, delivering radiotherapy even to small-volume tumors, (2) the long half-life of $\sim 7$ days that prolongs its anti-tumor effect, and 3) the short particle range of $1.5 \mathrm{~mm}$, limiting its cytotoxicity to the target tissue [52]. According to preclinical studies, ${ }^{177}$ Lu-DOTA-PSMA-617 ( ${ }^{177}$ Lu-PSMA), a PSMAtargeted small molecule, had shown high uptake and retention in $\mathrm{MPC}$ cells, and lower uptake in normal PSMA-expressing cells, such as in the kidney [53, 54]. This selective property and recent clinical activity render ${ }^{177} \mathrm{Lu}-\mathrm{PSMA}$ an exciting radioligand currently in clinical development for mPC [55]. In a single-arm phase-2 trial investigating ${ }^{177} \mathrm{Lu}$-PSMA in 30 patients with $\mathrm{mCRPC}$ who had progressed despite extensive prior therapy [56], 17/30 (57\%) had $>50 \%$ PSA decline, and $14 / 17$ (82\%) patients with measurable disease had an OR. These data were reinforced in a follow-up analysis of the same cohort (with 20 additional patients) on later follow-up, with $64 \%$ of patients experiencing $>50 \%$ PSA decline. In patients treated with ${ }^{177} \mathrm{Lu}$-PSMA, median PSA PFS was 6.9 months (95\% CI 6.0-8.7) [57]. Patients predominantly had disease progression in the bone marrow and in the liver. The two most common reasons for treatment discontinuation of ${ }^{177} \mathrm{Lu}$-PSMA were leukoerythroblastic pancytopenia and liver metastases [58]. The observed preliminary clinical efficacy prompted two larger randomized controlled trials (RCTs): a phase-2 trial randomizing 200 patients to either ${ }^{177} \mathrm{Lu}$-PSMA or cabazitaxel (TheraP-NCT03392428) and a phase-3 trial randomizing 750 patients to ${ }^{177} \mathrm{Lu}$-PSMA plus standard of care or standard care alone (VISION-NCT03511664). The TheraP study selected patients with PSMA-positive mCRPC progressing after docetaxel. The trial treated 98 patients with ${ }^{177} \mathrm{Lu}$-PSMA and 85 patients with standard-of-care cabazitaxel. Recently presented data from this study showed that $66 \%$ of patients treated with ${ }^{177} \mathrm{Lu}$-PSMA vs. $37 \%$ of patients treated with cabazitaxel achieved the primary endpoint of $\geq 50 \%$ PSA decline, a $29 \%$ absolute increase in the $\geq 50 \%$ PSA decline response (95\% CI $16-42 \% ; p<0.0001)$. In addition, at a median follow-up of 13.3 months, ${ }^{177} \mathrm{Lu}$-PSMA was shown to significantly improve PSA PFS (HR 0.69, 95\% CI 0.50$0.95 ; p=0.02$ ) [59]. Patients treated with ${ }^{177} \mathrm{Lu}$-PSMA also had fewer grade 3/4 AEs, most common of which were thrombocytopenia (11\%), anemia (8\%), and fatigue (5\%). These results suggest that ${ }^{177} \mathrm{Lu}$-PSMA represents an effective therapy in patients with mCRPC and high PSMA expression. Further clinical development of ${ }^{177} \mathrm{Lu}-$ PSMA is ongoing; the VISION study has completed enrollment of 750 patients and will subsequently report on its primary endpoint of overall survival [60]. This trial will pave the registrational path for potential approval from the US FDA for ${ }^{177} \mathrm{Lu}$-PSMA $[55,61]$.

\section{Immunotherapy}

In recent years, immunotherapy has emerged as a treatment option for many malignancies with beneficial and durable responses [62-64]. The central principle is to enhance the anti-tumor activity of $\mathrm{CD} 8+$ cytotoxic $\mathrm{T}$ lymphocytes (CTLs), either by stimulating their activation against tumor-associated antigens (TAAs) or by blocking the immune-suppressing signals that decrease the number and exhaust the cytotoxic function of CTLs.

\section{Tumor-associated antigen-directed therapies}

Multiple methods have been utilized to induce a $\mathrm{T}$ cell response against TAA-expressing tumor cells [64]. Monoclonal antibodies (mAbs) directly target a TAA, marking the tumor cell for destruction via multiple pathways: (1) activation of the complement system, (2) antibodydependent cytotoxic $\mathrm{T}$ cell activation, or (3) enhancing uptake by phagocytes, followed by presentation to immature $\mathrm{T}$ cells. Vaccination is an alternative method to trigger immune response, either by direct administration of an antigen along with costimulatory molecules, or by stimulating a patient's leukapheresed immune cells with an antigen ex vivo and reinfusing the cells. The above mechanism was the basis for sipuleucel-T, the first vaccine-based FDA-approved cancer therapy, which prolonged OS in mCRPC [65]. Interestingly, a recently published analysis of a registry of patients who received $\geq 1$ sipuleucel-T infusion showed an OS difference between African-American and Caucasian patients in both the all-patient set ((HR 0.81, 95\% CI 0.68-0.97, $p=0.03$ ) and the PSA-matched patient subset (HR 0.70, $95 \%$ CI 0.57-0.86, $p<0.001)$. In particular, with a median follow-up of 46.6 months, the median OS for AfricanAmerican patients was 35.3 versus 25.8 months for Caucasian patients, and this difference was greater, 54.3 versus 33.4 months, respectively, in patients who were treated at lower baseline PSA levels (HR 0.52, 95\% CI $0.37-0.72, p<0.001)[66]$. 
A third TAA-directed modality involves inducing the patient's own dendritic cells (DCs) to generate a $\mathrm{T}$ cell response against TAAs, either by loading them with antigen ex vivo or by genetically modifying them to present TAA. Table 2 presents TAAs specific to $\mathrm{MPC}$ that have been identified as targets for vaccines in mCRPC.

Despite previous promising data from a phase- 2 clinical trial on identifying other TAA-directed targets, two phase-3 clinical trials have failed to meet their clinical endpoints: PROSTVAC (targeting PSA) and GVAX (cellular vaccine with two irradiated prostate cancer cell lines) $[67,68]$. Currently, concurrent administration of DCVAV with standard chemotherapy (docetaxel) is under investigation in a randomized, double-blinded, multicenter phase-3 study (VIABLE, NCT02111577).

\section{Immune checkpoint inhibitor therapy}

Immune checkpoint inhibitor (ICI) therapy has shown clinical benefit in a number of solid tumors (e.g., metastatic melanoma, non-small cell lung cancer, renal cell carcinoma, and urothelial cancer, among others), but unfortunately these observations have not been replicated in patients with mCRPC $[69,70]$. Factors such as low tumor mutational burden (TMB), loss of tumor suppressors (such as PTEN), low prevalence of DDR genetic defects, and silencing of major histocompatibility complex-1 (MHC-1) expression may all contribute to mCRPC's relative lack of response to ICI therapy [71]. Two early phase- 3 studies of the anti-cytotoxic T lymphocyte-associated protein-4 (CTLA-4) antibody ipilimumab both failed to meet their primary endpoint of improved OS [69, 70]; however, recent studies investigating the efficacy of the programmed death-1 inhibitor

Table 2 Tumor-associated antigens (TAAs) in mPC immunotherapeutics

\begin{tabular}{|c|c|c|c|c|c|c|}
\hline TAA & Function & $\begin{array}{l}\text { Modalities } \\
\text { for immunotherapy }\end{array}$ & $\begin{array}{l}\text { Other expressing } \\
\text { tissues }\end{array}$ & $\begin{array}{l}\text { Unsuccessful } \\
\text { therapies }\end{array}$ & Approved therapies & Ongoing trials \\
\hline PSMA & $\begin{array}{l}\text { Zinc metalloenzyme } \\
\text { Folate uptake }\end{array}$ & $\begin{array}{l}\text { Bi-specific antibodies, } \\
\text { CAR-T, STEAP-1 }\end{array}$ & Salivary glands, kidney & $\mathrm{N} / \mathrm{A}$ & N/A & $\begin{array}{l}\text { PSMAxCD3 } \\
\text { antibody CC-1 } \\
\text { (NCT04104607), } \\
\text { P-PSMA-101 CAR-T } \\
\text { (NCT04249947), } \\
\text { PSCA-CAR-T } \\
\text { (NCT03873805), } \\
\text { CART-PSMA- } \\
\text { TGFBRDN } \\
\text { (NCT04227275), } \\
\text { BPX-601 CAR-T } \\
\text { (NCT02744287), } \\
\text { AMG 509 } \\
\text { (NCT04221542), } \\
\text { Pasotuxizumab } \\
\text { (BAY 2010112) } \\
\text { (NCT01723475), } \\
\text { ES414 } \\
\text { (NCT02262910), } \\
\text { Adoptive transfer of } \\
\text { autologous T cells } \\
\text { (NCT01140373) }\end{array}$ \\
\hline PAP & $\begin{array}{l}\text { Seminal fluid produc- } \\
\text { tion }\end{array}$ & Vaccine $+\mid \mathrm{Cl}$ & Not significant & $\mathrm{N} / \mathrm{A}$ & Sipuleucel-T & $\begin{array}{l}\text { NCT04090528, } \\
\text { NCT02499835 }\end{array}$ \\
\hline PSA & $\begin{array}{l}\text { Serine protease } \\
\text { Forms semen coagu- } \\
\text { lum }\end{array}$ & Vaccine $+\mathrm{ICl}$ & Not significant & $\begin{array}{l}\text { Vaccine } \\
\text { (NCT01322490) }\end{array}$ & N/A & $\begin{array}{l}\text { NCT02933255, } \\
\text { NCT02325557 }\end{array}$ \\
\hline MUC1 & $\begin{array}{l}\text { Cell adhesion, intra- } \\
\text { cellular signaling }\end{array}$ & Vaccine, DC vaccine & $\begin{array}{l}\text { Most epithelial cells. } \\
\text { Many adenocarcino- } \\
\text { mas. Not expressed } \\
\text { by normal prostate } \\
\text { cells }\end{array}$ & $\mathrm{N} / \mathrm{A}$ & $\mathrm{N} / \mathrm{A}$ & NCT03481816 \\
\hline PSCA & Unknown & Vaccine, $\mathrm{mAb}$ & Not significant & N/A & N/A & N/A \\
\hline TARP & $\begin{array}{l}\text { Androgen regulation. } \\
\text { Mitochondrial lipid } \\
\text { metabolism }\end{array}$ & DC vaccine & $\begin{array}{l}\text { Breast adenocarci- } \\
\text { noma }\end{array}$ & $\mathrm{N} / \mathrm{A}$ & $\mathrm{N} / \mathrm{A}$ & NCT02362451 \\
\hline
\end{tabular}

PSMA prostate-specific membrane antigen, PAP prostate acid phosphatase, PSA prostate-specific antigen, MUC1 mucin-1, PSCA prostate stem cell antigen, STEAP-1 six transmembrane epithelial antigen of the prostate $1, T A R P T$ cell receptor gamma chain alternate reading frame protein, $C A R-T$ chimeric antigen receptor T cell, ICI immune checkpoint inhibitor therapy, $D C$ dendritic cell, $m A b$ monoclonal antibody 
(PD-1) pembrolizumab have shown promising responses in patients with mCRPC. In a single-site cohort of 48 patients with mCRPC treated with pembrolizumab, $17 \%$ had $\geq 50 \%$ PSA decline with $8 \%$ (4/48 patients) having $\geq 90 \%$ PSA decline as best response [72]. These exceptional responders were found to have molecular changes (microsatellite instability-high (MSI-H), TMBhigh, and mutation in $L R P 1 b$ ), which predispose to antiPD-1 responses.

In the phase-2 KEYNOTE-199 study, patients with mCRPC were enrolled into one of five cohorts based on their measurable disease status, tumor PD-L1 status (by combined positive score, CPS), and prior enzalutamide experience and assigned to treatment with pembrolizumab monotherapy (cohorts 1-3 [73]) or pembrolizumab with enzalutamide (cohorts 4 and 5 [74]). In the pembrolizumab monotherapy cohorts, 133 patients with RECIST-measurable, PD-L1-positive MCRPC were enrolled in cohort 1, 66 patients with RECIST-measurable, PD-L1-negative mCRPC in cohort 2 , and 59 patients with bone-predominant $\mathrm{mCRPC}$ in cohort 3 . Biochemical response occurred in $23 \%$ of patients, with PSA stability in $9 \% . \geq 50 \%$ PSA decline (PSA50) was noted in $9 \%$, and $5 \%$ experienced $\geq 90 \%$ PSA reduction. The ORR was $5 \%(95 \%$ CI $2-11 \%)$ in cohort 1 and $3 \%(95 \% \mathrm{CI}<1 \%$ to $11 \%$ ) in cohort 2 . Interesting data emerged for duration of response (DOR) in this population of patients with those in cohort 1 having a median DOR that was not reached (range 1.9 to $\geq 21.8$ months), while those in cohort 2 had a median DOR of 10.6 months (range 4.416.8 months). The median rPFS was 2.1 months (95\% CI 2.0-2.1 months), 2.1 months (95\% CI $2.0-3.3$ months), and 3.7 months (95\% CI 2.1-4.2 months) in cohorts 1, 2, and 3, respectively. Moreover, in cohort 1, the median OS was 9.5 months (95\% CI 6.4-11.9 months), in cohort 2 was 7.9 months (95\% CI 5.9-10.2 months), and in cohort 3 was 14.1 months (95\% CI 10.8-17.6 months), while the estimated 12-month survival rates were $41 \%, 35 \%$, and $62 \%$, respectively. Up to $60 \%$ of the patients in this study experienced at least one treatment-related $\mathrm{AE}$, and the most common AEs were fatigue, diarrhea, and decreased appetite. Also, one or more grade 3-5 treatment-related AEs were identified in $15 \%$ of these patients, $5 \%$ discontinued the treatment due to AEs, and two patients died due to pneumonitis and sepsis that were considered as treatment-related AEs [73].

While pembrolizumab monotherapy demonstrated promising responses in patients with $\mathrm{mCRPC}$ based on their durability, objective response rates were still low (3-5\%) and therefore pembrolizumab was combined with enzalutamide cohorts 4 and 5 of Keynote 199. A previous single-institution study of concurrent pembrolizumab with enzalutamide in 10 patients with $\mathrm{mCRPC}$, who had previously progressed on enzalutamide monotherapy, found that the combination can elicit regained and durable responses [75]. KEYNOTE-199 enrolled 81 men in cohort 4 and 45 men in cohort 5 . All men had prior progression of disease on enzalutamide, and pembrolizumab was added to enzalutamide as further treatment. In cohort 4 , the ORR was $12 \%$ including $2 \%$ complete responses, and $51 \%$ of patients achieved disease control in both the measurable (cohort 4 ) and bone-only metastatic (cohort 5) populations [74].

Other pembrolizumab combinations are in clinical development to improve the efficacy of known effective treatments for mCRPC. A phase $1 \mathrm{~b} / 2$ trial (KEYNOTE-365) investigated the efficacy and safety of the concurrent pembrolizumab with olaparib in patients with $\mathrm{mCRPC}$ who previously progressed while on docetaxel. The updated results reported that $9 \%$ achieved PSA responses, and the median time to PSA progression was 16 weeks (95\% CI 12-19). The median rPFS and OS were 4 months (95\% CI 3-8) and 14 months (95\% CI 8-19), respectively. Any treatment-related AEs occurred in $70(83 \%)$ patients, including most commonly nausea (33\%) and anemia (31\%), as well as grade 3-5 AEs in 29 (35\%) patients [76].

Since May 2019, an ongoing phase-3 trial (KEYLYNK-010) is currently enrolling patients to compare the combination of pembrolizumab and olaparib with investigator's choice of either enzalutamide or abiraterone acetate. The primary endpoints of the study include rPFS and OS [77]. Another ongoing phase-3 trial (KEYNOTE-921) is investigating the combination of pembrolizumab and docetaxel in chemotherapy-naïve mCRPC patients, who have already progressed while on enzalutamide or abiraterone. The primary endpoints of this study include rPFS and OS [78]. A third randomized, double-blind phase-3 clinical trial (KEYNOTE-991), with an estimated number of participants above 1,200 , is also accruing patients to the treatment of pembrolizumab with enzalutamide and ADT compared to enzalutamide and ADT in patients with $\mathrm{mHSPC}$. The completion of these three phase- 3 trials may expand treatment options for patients with $\mathrm{mPC}$ to include pembrolizumab combinations.

Another PD-1 inhibitor, nivolumab, has also been studied in combination with docetaxel, rucaparib, or enzalutamide in a phase-2 trial (CHECKMATE-9KD) for patients with mCRPC. In 41 patients treated with nivolumab and docetaxel, the ORR was $36.8 \%$, with 1 complete and 6 partial responses. In addition, the confirmed PSA response was $46.3 \%$ (95\% CI 30.7-62.6\%), the median rPFS was 8.2 months (95\% CI 6.6-not reached), and the 6-month rPFS rate was $71.5 \%$. Any grade AEs occurred in almost all (92.7\%) patients, and grade $3 / 4$ AEs occurred in $48.8 \%$ of patients [79]. 
Finally, a phase-3 trial (IMbassador250) compared the anti-PD-L1 therapy atezolizumab with enzalutamide with enzalutamide alone in 759 patients with mCRPC. No difference was found in disease control between the two cohorts. In particular, the reported rPFS was 4.2 months (4.1-5.3) for combination of atezolizumab and enzalutamide versus 4.1 months for enzalutamide alone (3.7-4.5) (HR 0.90, 95\% CI 0.75-1.07, $p=0.24$ ), and time to PSA progression was 2.8 months versus 2.8 months (HR 1.04 95\% CI 0.87-1.24, $p=0.6857$ ). Median OS did not differ between the combination versus enzalutamide alone (15.2 months vs. 16.6 months, HR 1.12, 95\% CI $0.91-$ 1.37, $p=0.28$ ). $12.2 \%$ Grade 3-5 AEs were reported in the atezolizumab plus enzalutamide cohort versus $1.3 \%$ in the enzalutamide cohort.

There are special populations of patients with prostate cancer in whom we may be able to enrich for response to immunotherapies. One of these special population is patients with MSI-H tumors. The US FDA approved pembrolizumab for patients with unresectable or metastatic, MSI-H or mismatch repair-deficient (dMMR) solid tumors in 2017, based on five separate single-cohort studies. Of the 149 patients who were pooled together, two patients had prostate cancer. One patient had a partial response and the second had stable disease [80]. A subsequent study enrolled 233 patients with MSI-H non-colorectal cancers, of whom 6 patients had prostate cancer. Across the cohort, the objective response rate was $34.3 \%$ and median duration of response had not been reached, with majority of responders (78\%) having responses greater than 2 years [81]. Given this efficacy across tumor types, patients with metastatic prostate cancer are now recommended to undergo testing for MSI-H status, with a prevalence in this population around 3\% [82, 83]. Recently published studies further support the efficacy of PD-1 inhibition in patients with MSI-H mCRPC. In a case series of 23 patients with MSIH/ dMMR mCRPC, 11 patients were treated with antiPD-1/PD-L1 therapy and 6 patients (54.4\%) achieved $\mathrm{a} \geq 50 \%$ PSA decline. Radiographic responses occurred in 4 out of these 6 patients, and 5 patients were still on therapy for as long as 89 weeks [83]. Graham et al. recently reported that of a total of 17 patients with dMMR and/ or MSI-H mPC who received pembrolizumab, 53\% had $a \geq 50 \%$ PSA reduction, and $87.5 \%$ of them remained on treatment at a median follow-up of 12 months [84]. Taking into account the above findings, microsatellite testing should be undertaken and pembrolizumab considered for patients with MSI-H status.

Through a downstream impact on modulation of DNA repair pathways and hence genomic instability, those patients with mCRPC who harbor cyclin-dependent kinase 12 (CDK12) loss appear to respond well to immune checkpoint inhibition. CDK12 was shown to phosphorylate RNA polymerase, contributing to homologous recombination repair. With biallelic CDK12 loss, homologous recombination repair is impaired, inducing an immunogenic subtype of $\mathrm{mCRPC}$ with elevated neoantigen burden, increased T-cell infiltration and clonal expansion. Two of four patients who had CDK12 loss had significant PSA responses to anti-PD1 monotherapy [85]. According to a recently published multicenter retrospective study of 52 patients with $C D K 12$-mutated prostate cancer, at a median follow-up of 8.2 years (95\% CI 5.611.1), 49 of 52 (94\%) patients developed metastatic disease. The median OS from metastasis was 3.9 years $(95 \%$ CI 3.2-8.1). For the 19 patients treated with any ICI, the $>50 \%$ PSA decline rate was $11 \%$, and the estimated 9-month PFS was 23\% [86]. Another retrospective multicenter study identified 60 patients with at least monoallelic $C D K 12$ alterations. In this series, nine patients who had CDK12 alterations were treated with either pembrolizumab or nivolumab, of whom $33.3 \%$ (3/9) had a PSA response and a median PFS of 5.4 months [87]. This suggests $C D K 12$ deficiency contributes to impaired HRR and has been shown to associate with immunotherapy response.

Completed and ongoing clinical trials investigating different ICI agents in patients with $\mathrm{mPC}$ have been summarized (Table 3). Although monotherapy ICIs have not been successful, there are many ongoing trials to combine ICIs with standard chemotherapies or targeted therapies in order to improve clinical outcomes.

\section{Other immunotherapeutic targets}

Toll-like receptor (TLR)-3 is a pattern recognition receptor expressed on DCs. After binding to double-stranded ribonucleic acid (dsRNA) produced by virus-infected cells, DC-mediated cytokine release can activate TAAspecific CTLs. TLR-3 activation serves as an adjunct to the priming of CTLs [88, 89]; multiple ongoing trials are investigating the combination of TLR-3 agonist polyICLC (an analogue of viral dsRNA) with an ICI agent to produce a more robust immune response in patients with mPC (NCT02643303, NCT03835533).

The adenosine signaling pathway is another attractive target for further investigation in oncology. The adenosine $2 \mathrm{~A}$ receptor (A2AR) is expressed on a wide variety of immune cells (particularly $\mathrm{T}$ cells) $[89,90]$. Inhibiting or knocking out A2AR in preclinical models led to tumor regression, spurring the development of the oral A2AR antagonist CPI-444 (ciforadenant), currently in a phase $1 / 1 \mathrm{~b}$ trial of 336 patients, alone and in combination with atezolizumab in the treatment of various metastatic solid tumors, including mCRPC (NCT02655822). Another A2AR antagonist, 
Table 3 Ongoing clinical trials investigating the administration of immune checkpoint inhibitor agents in patients with $\mathrm{MPC}$

\begin{tabular}{|c|c|c|c|c|}
\hline Mechanism & Agent & $\begin{array}{l}\text { Concurrent administered agent } \\
\text { (Clinicaltrials.gov identifier) }\end{array}$ & Clinicaltrials.gov identifier & $\begin{array}{l}\text { Other ongoing trials } \\
\text { (number of subjects) }\end{array}$ \\
\hline \multirow[t]{6}{*}{ Anti-PD1 } & \multirow[t]{2}{*}{ Nivolumab } & $\begin{array}{l}\text { 1. I pilimumab (followed by nivolumab } \\
\text { maintenance therapy) }\end{array}$ & 1. NCT03570619-IMPACT & \multirow{2}{*}{$\begin{array}{l}\text { NCT03835533 (45) } \\
\text { NCT03600350 (41) } \\
\text { NCT02933255 (29) } \\
\text { NCT02601014 (15) }\end{array}$} \\
\hline & & 2. Rucaparib, docetaxel, or enzalutamide & 2. NCT03338790-Checkmate 9KD & \\
\hline & \multirow[t]{4}{*}{ Pembrolizumab } & 1. Docetaxel & 1. NCT03834506-KEYNOTE-921 & NCT02499835 (72) \\
\hline & & 2. Enzalutamide & 2. NCT03834493-KEYNOTE-641 & NCT04090528 (60) \\
\hline & & 3. Olaparib & 3. NCT03834519-KEYLYNK-010 & NCT02325557 (51) \\
\hline & & $\begin{array}{l}\text { 4. (a) olaparib, (b) docetaxel + prednisone, } \\
\text { (c) enzalutamide, (d) abiraterone + pred- } \\
\text { nisone }\end{array}$ & 4. NCT02861573/KEYNOTE-365 & NCT03093428 (45) \\
\hline Anti-PDL1 & Atezolizumab & Enzalutamide & NCT03016312-IMbassador250 & NCT02655822 (336) \\
\hline \multirow[t]{2}{*}{ Anti-PDL1 + anti-CTLA-4 } & \multirow{2}{*}{$\begin{array}{l}\text { Durvalumab }+ \\
\text { tremelimumab }\end{array}$} & Tremelimumab (IV) & 1. NCT03204812 & \multirow[t]{2}{*}{ NCT02484404 (384) } \\
\hline & & 2. Tremelimumab (vaccine) plus PolyICLC & 2. NCT02643303 & \\
\hline \multirow[t]{2}{*}{ Anti-CTLA4 } & \multirow[t]{2}{*}{ Ipilimumab } & 1. ADT & 1. NCT01377389 & \\
\hline & & 2. Abiraterone acetate + prednisone & 2. NCT01688492 & \\
\hline
\end{tabular}

AZD4635, is also currently in development, with an ongoing phase- 2 trial in combination with either durvalumab or oleclumab for treatment of $\mathrm{mCRPC}$ (NCT04089553). These novel therapeutic strategies for $\mathrm{mCRPC}$ may expand future treatment options in this aggressive and terminal disease state (Fig. 1).
Emerging strategies for the discovery of novel therapeutics in $\mathrm{mCRPC}$ :

Novel targets and treatment options cannot be developed without new preclinical models and platforms to find new mechanisms of resistance and targets for future treatments. Metastatic castrate-resistant prostate cancer (mCRPC) patient-derived xenografts (PDXs) recapitulate the genetic and phenotypic diversity of the disease. According to recently published data, LuCaP PDX/

\section{PARP inhibitors}

FDA approved: olaparib and rucaparib for select populations with DNA damage repair mutations

In clinical development: veliparib, niraparib, talozoparib

\section{Radiopharmaceuticals}

${ }^{177}$ Lutetium-PSMA-617

\section{Metastatic Castration-} Resistant Prostate Cancer

\section{Immunotherapy}

1. Tumor-associated antigen-directed therapies 2. Immune checkpoint inhibitor therapy 3. Other immunotherapeutic targets

\section{Androgen receptor inhibitors}

Proteolysis Targeting Chimeras (PROTACs) for AR degradation

ARV-110, ARCC-4, ARD-61

Fig. 1 Summary of novel therapeutic categories in metastatic castration-resistant prostate cancer 
organoid models provide an expansive, genetically characterized platform to evaluate mechanisms of pathogenesis as well as therapeutic responses and their molecular correlates in mCRPC [91]. Furthermore, the application of a focused CRISPR-Cas9 screen showed that the concurrent inhibition of RNAP2 and RBX1 profoundly suppresses the growth of CRPC in a synergistic manner, which potentiates the therapeutic efficacy of the RNAP2 inhibitor, $\alpha$-amanitin-based antibody drug conjugate (ADC) [92]. Moreover, the development of another novel CRISPR-mediated knock-in cell line has showed that PARP inhibitors down-regulate AR signaling and concurrently attenuate androgenic cell growth and promote 'BRCAness' to sensitize cells to DNA-damaging agents [93]. In parallel, omics-driven potential drug targets have been evaluated in preclinical models and even in clinical trials, holding promising therapeutic treatment options in patients with advanced PC [94].

\section{Conclusions}

Patients with mCRPC eventually have disease progression on cytotoxic chemotherapy and androgen-axis-targeting drugs, contributing to an ongoing clinical need for novel treatment approaches. The recently US FDAapproved PARP inhibitors, olaparib and rucaparib, have emerged as a treatment option in patients with mCRPC and HRR mutations. In addition, recent results suggest that ${ }^{177} \mathrm{Lu}$-PSMA may offer a potentially effective therapeutic option in patients with $\mathrm{MCRPC}$ and high PSMA expression. Patient selection by molecular and genetic markers also offers potential utility for various immunotherapies in mCRPC. Other classes of novel treatments such as AR degraders are still in clinical development. Further clinical development of these novel treatment agents, either alone or in combination with prostate-cancer targeting therapies, will be essential to frame optimal management strategies for this challenging disease. The landscape of treatment options thus continues to expand for patients with mCRPC.

\footnotetext{
Abbreviations

PC: Prostate cancer; mCRPC: Metastatic castration-resistant prostate cancer; PARP: Poly ADP-ribose polymerase; MPC: Metastatic prostate cancer; ADT: Androgen deprivation therapy; HSPC: Hormone-sensitive prostate cancer; CRPC: Castration-resistant prostate cancer; US FDA: United States Food and Drug Administration; SSBs: Single-strand DNA breaks; DSBs: Double-strand breaks; HRR: Homologous recombination repair; NHEJ: Non-homologous end-joining; PFS: Progression-free survival; OS: Overall survival; OR: Objective response; PSA: Prostate-specific antigen; rPFS: Radiographic PFS; ORR: Objective response rate; AEs: Adverse events; AR: Androgen receptor; nmCRPC: Non-metastatic CRPC; MFS: Metastasis-free survival; PSMA: Prostate-specific membrane antigen; PET: Positron emission tomography; RCT: Randomized controlled trial; CTLs: Cytotoxic T lymphocytes; TAAs: Tumor-associated antigens; mAbs: Monoclonal antibodies; DCs: Dendritic cells; ICl: Immune checkpoint inhibitor; TMB: Tumor mutational burden; MHC-1: Major histocompatibility complex-1; CTLA-4: Cytotoxic T lymphocyte-associated protein-4;
}

PD-1: Programmed death-1 inhibitor; MSI-H: Microsatellite instable-high; DOR: Duration of response; dMMR: Mismatch repair deficient; TLR-3: Toll-like receptor; A2AR: Adenosine 2A receptor; PDXs: Patient-derived xenografts.

\section{Acknowledgements}

We thank the academic environment at Duke Cancer Institute Center for Prostate and Urologic Cancers and Duke Department of Medicine for the time and effort dedicated to writing this manuscript.

\section{Authors' contributions}

EP and GSK wrote the initial manuscript and designed tables; TZ designed the initial outline, contributed to writing and finalized the manuscript. All authors read and approved the final manuscript.

\section{Funding}

None.

\section{Availability of data and materials}

Not applicable.

Ethics approval and consent to participate

Not applicable.

\section{Consent for publication}

Not applicable.

\section{Competing interests}

TZ: research funding (to Duke) from Pfizer, Janssen, Acerta, Abbvie, Novartis, Merrimack, OmniSeq, PGDx, Merck, Mirati, and Astellas; consulting/speaking with Genentech Roche, Exelixis, Genomic Health, and Sanofi Aventis; and consulting with AstraZeneca, Bayer, Pfizer, Foundation Medicine, Janssen, Amgen, BMS, MJH Associates, and IQVIA. Stock ownership/employment/ consulting (spouse) from Capio Biosciences, Archimmune Therapeutics, \& Nanorobotics. CJH: Research funding from Merck, consulting from Merck, BMS, Seattle Genetics, Eisai, Bayer, Genentech; Speakers bureau for BMS, Eisai, Genentech. AJA: Consulting with Pfizer, Astellas, Janssen, Bayer, Astrazeneca, and Merck and research funding (to Duke) from Pfizer, Astellas, Janssen, Bayer, Dendreon, Novartis, Genentech/Roche, Merck, BMS, Astrazeneca, Constellation, and Beigene, DJG: Research from Acerta Pharmaceuticals, Astellas, Bayer, BMS, Calithera, Exelixis, Janssen Pharmaceuticals, Novartis, Pfizer, Sanofi Aventis; Consultant or Advisory board for Astellas, AstraZeneca, Axess Oncology, Bayer H/C Pharmaceuticals, BMS, Capio Biosciences, Exelixis, Flatiron, Janssen, Merck, MJH Associates, Modra Pharmaceuticals, Myovant Sciences, Physician Education Resource LLC, Pfizer, Sanofi Aventis, and Vizuri Health Sciences LLC; Honoraria or travel fees from Bayer, EMD Serono, Exelixis, Ipsen, MJH Associates, Pfizer, Sanofi Aventis, UroGPO, and UroToday. MRH: Acerta; research funding, Astellas; research funding, AstraZeneca; research funding, consulting, Bayer; research funding, consulting, Bristol Myers Squibb; research funding, consulting, Clovis Oncology; research funding, Exelixis; research funding, consulting, promotional speaking, FujiFilm; consulting, Genentech; consulting, promotional speaking, Janssen; consulting, Merck; research funding, Pfizer; research funding, consulting, Seattle Genetics; research funding EP, GSK, CK: None.

\section{Author details \\ ${ }^{1}$ Department of Medicine, Duke University, Durham, NC 27710, USA. ${ }^{2}$ Divi- sion of Medical Oncology, Department of Medicine, Duke University, DUMC 103861, Durham, NC 27710, USA. ${ }^{3}$ Duke Cancer Institute Center for Prostate and Urologic Cancers, Durham, NC 27710, USA. ${ }^{4}$ Department of Pharmacol- ogy and Cancer Biology, Duke University, Durham, NC 27710, USA.}

Received: 3 September 2020 Accepted: 11 October 2020

Published online: 28 October 2020

References

1. Siegel RL, Miller KD, Jemal A. Cancer statistics, 2020. CA Cancer J Clin (Internet). 2020;70:7-30 
2. Sweeney CJ, Chen YH, Carducci M, Liu G, Jarrard DF, Eisenberger M, et al. Chemohormonal therapy in metastatic hormone-sensitive prostate cancer. N Engl J Med (Internet). 2015;373:737-46.

3. James ND, Sydes MR, Clarke NW, Mason MD, Dearnaley DP, Spears $M R$, et al. Addition of docetaxel, zoledronic acid, or both to first-line long-term hormone therapy in prostate cancer (STAMPEDE): survival results from an adaptive, multiarm, multistage, platform randomised controlled trial. Lancet (Internet). 2016;387:1163-77.

4. Armstrong AJ, Szmulewitz RZ, Petrylak DP, Holzbeierlein J, Villers A, Azad A, et al. Arches: a randomized, phase III study of androgen deprivation therapy with enzalutamide or placebo in men with metastatic hormone-sensitive prostate cancer. J Clin Oncol (Internet). 2019:37:2974-86

5. Davis ID, Martin AJ, Stockler MR, Begbie S, Chi KN, Chowdhury S, et al. Enzalutamide with standard first-line therapy in metastatic prostate cancer. N Engl J Med (Internet). 2019;381:121-31.

6. Chi KN, Agarwal N, Bjartell A, Chung BH, Gomes AJPDS, Given R, et al. Apalutamide for metastatic, castration-sensitive prostate cancer. N Engl J Med (Internet). 2019;381:13-24.

7. O'Connor MJ. Targeting the DNA damage response in cancer. Mol Cell (Internet). 2015;60:547-60.

8. Moynahan ME, Jasin M. Mitotic homologous recombination maintains genomic stability and suppresses tumorigenesis. Nat Rev Mol Cell Biol (Internet). 2010;11:196-207.

9. Lord CJ, Ashworth A. PARP inhibitors: synthetic lethality in the clinic. Science (80-) (Internet). 2017;355:1152-8.

10. Wiggans AJ, Cass GK, Bryant A, Lawrie TA, Morrison J. Poly(ADP-ribose) polymerase (PARP) inhibitors for the treatment of ovarian cancer. Cochrane Database Syst Rev (Internet). 2015;2015:CD007929.

11. Ledermann J, Harter P, Gourley C, Friedlander M, Vergote I, Rustin G, et al. Olaparib maintenance therapy in platinum-sensitive relapsed ovarian cancer. N Engl J Med (Internet). 2012;366:1382-92.

12. Moore K, Colombo N, Scambia G, Kim BG, Oaknin A, Friedlander $\mathrm{M}$, et al. Maintenance Olaparib in patients with newly diagnosed advanced ovarian cancer. N Engl J Med (Internet). 2018;379:2495-505.

13. Sandhu SK, Omlin A, Hylands L, Miranda S, Barber LJ, Riisnaes R, et al. Poly (ADP-ribose) polymerase (PARP) inhibitors for the treatment of advanced germline BRCA2 mutant prostate cancer. Ann Oncol (Internet). 2013;24:1416-8.

14. Mateo J, Carreira S, Sandhu S, Miranda S, Mossop H, Perez-Lopez R, et al. DNA-repair defects and olaparib in metastatic prostate cancer. N Engl J Med (Internet). 2015;373:1697-708

15. Mateo J, Porta N, Bianchini D, McGovern U, Elliott T, Jones R, et al. Olaparib in patients with metastatic castration-resistant prostate cancer with DNA repair gene aberrations (TOPARP-B): a multicentre, open-label, randomised, phase 2 trial. Lancet Oncol (Internet). 2020;21:162-74.

16. de Bono J, Mateo J, Fizazi K, Saad F, Shore N, Sandhu S, et al. Olaparib for metastatic castration-resistant prostate cancer. N Engl J Med (Internet). 2020;382:2091-102

17. Abida W, Campbell D, Patnaik A, Sautois B, Shapiro J, Vogelzang NJ et al. Preliminary results from the TRITON2 study of rucaparib in patients with DNA damage repair (DDR)-deficient metastatic castration-resistant prostate cancer (mCRPC): updated analyses (internet) 2019. https://www.clovi soncology.com/media/1160/esmo2019_wabida_poster.pdf.

18. Asim M, Tarish F, Zecchini HI, Sanjiv K, Gelali E, Massie CE, et al. Synthetic lethality between androgen receptor signalling and the PARP pathway in prostate cancer. Nat Commun (Internet). 2017;8:374.

19. Clarke N, Wiechno P, Alekseev B, Sala N, Jones R, Kocak I, et al. Olaparib combined with abiraterone in patients with metastatic castration-resistant prostate cancer: a randomised, double-blind, placebo-controlled, phase 2 trial. Lancet Oncol (Internet). 2018;19:975-86.

20. Hussain M, Daignault-Newton S, Twardowski PW, Albany C, Stein MN, Kunju LP, et al. Targeting androgen receptor and DNA repair in metastatic castration-resistant prostate cancer: results from NCI 9012. J Clin Oncol (Internet). 2018:36:991-9.

21. Pommier Y, O'Connor MJ, de Bono J. Laying a trap to kill cancer cells: PARP inhibitors and their mechanisms of action. Sci Transl Med (Internet). 2016;8:362ps17.

22. Pezaro C. PARP inhibitor combinations in prostate cancer. Ther Adv Med Oncol (Internet). 2020;12:1758835919897537.
23. Attard G, Richards J, de Bono JS. New strategies in metastatic prostate cancer: targeting the androgen receptor signaling pathway. Clin Cancer Res (Internet). 2011;17:1649-57.

24. Tran C, Ouk S, Clegg NJ, Chen Y, Watson PA, Arora V, et al. Development of a second-generation antiandrogen for treatment of advanced prostate cancer. Science (80-) (Internet). 2009;324:787-90.

25. Sanford M. Enzalutamide: a review of its use in metastatic, castrationresistant prostate cancer. Drugs (Internet). 2013;73:1723-32.

26. Scher HI, Fizazi K, Saad F, Taplin ME, Sternberg CN, Miller K, et al. Increased survival with enzalutamide in prostate cancer after chemotherapy. N Engl J Med (Internet). 2012;367:1187-97.

27. Beer TM, Armstrong AJ, Rathkopf DE, Loriot Y, Sternberg CN, Higano CS, et al. Enzalutamide in metastatic prostate cancer before chemotherapy. N Engl J Med (Internet). 2014;371:424-33.

28. Sternberg CN, Fizazi K, Saad F, Shore ND, De Giorgi U, Penson DF, et al. Enzalutamide and survival in nonmetastatic, castration-resistant prostate cancer. N Engl J Med (Internet). 2020;382:2197-206.

29. Smith MR, Mehra M, Nair S, Lawson J, Small EJ. Relationship between metastasis-free survival and overall survival in patients with nonmetastatic castration-resistant prostate cancer. Clin Genitourin Cancer (Internet). 2020;18:e180-9.

30. Smith MR, Saad F, Chowdhury S, Oudard S, Hadaschik BA, Graff JN, et al. Apalutamide treatment and metastasis-free survival in prostate cancer. N Engl J Med (Internet). 2018;378:1408-18.

31. Fizazi K, Shore N, Tammela TL, Ulys A, Vjaters E, Polyakov S, et al. Darolutamide in nonmetastatic, castration-resistant prostate cancer. N Engl J Med (Internet). 2019;380:1235-46.

32. Fizazi K, Shore ND, Tammela T, Ulys A, Vjaters E, Polyakov S, et al. Overall survival (OS) results of phase III ARAMIS study of darolutamide (DARO) added to androgen deprivation therapy (ADT) for nonmetastatic castration-resistant prostate cancer (nmCRPC). J Clin Oncol (Internet). 2020;2020:181.

33. Hird AE, Magee DE, Bhindi B, Ye XY, Chandrasekar T, Goldberg H, et al. A systematic review and network meta-analysis of novel androgen receptor inhibitors in non-metastatic castration-resistant prostate cancer. Clin Genitourin Cancer (Internet). 2020;51558-7673:30039-42.

34. Mori A, Hashimoto K, Koroki Y, Wu DB, Masumori N. The correlation between metastasis-free survival and overall survival in non-metastatic castration resistant prostate cancer patients from the medical data vision claims database in Japan. Curr Med Res Opin (Internet). 2019;35:1745-50.

35. Heidegger I, Brandt MP, Heck MM. Treatment of non-metastatic castration resistant prostate cancer in 2020: What is the best? Urol Oncol (Internet). 2020;38:129-36.

36. Neklesa TK, Winkler JD, Crews CM. Targeted protein degradation by PROTACs. Pharmacol Ther (Internet). 2017;174:138-44.

37. Salami J, Alabi S, Willard RR, Vitale NJ, Wang J, Dong H, et al. Androgen receptor degradation by the proteolysis-targeting chimera ARCC-4 outperforms enzalutamide in cellular models of prostate cancer drug resistance. Commun Biol (Internet). 2018;1:100.

38. Toure M, Crews CM. Small-molecule PROTACS: new approaches to protein degradation. Angew Chemie Int Ed (Internet). 2016;5:1966-73.

39. Kregel S, Wang C, Han X, Xiao L, Fernandez-Salas E, Bawa P, et al. Androgen receptor degraders overcome common resistance mechanisms developed during prostate cancer treatment. Neoplasia (United States) (Internet). 2020;22:111-9.

40. Petrylak DP, Gao X, Vogelzang NJ, Garfield MH, Taylor I, Moore MD, et al. First-in-human phase I study of ARV-1 10, an androgen receptor (AR) PROTAC degrader in patients (pts) with metastatic castrate-resistant prostate cancer (mCRPC) following enzalutamide (ENZ) and/or abiraterone (ABI). J Clin Oncol (Internet). 2020;38:15_suppl.3500.y

41. El-Amm J, Aragon-Ching JB. Targeting bone metastases in metastatic castration-resistant prostate cancer. Clin Med Insights Oncol (Internet). 2016;10:11-9.

42. Terrisse S, Karamouza E, Parker CC, Sartor AO, James ND, Pirrie S, et al. Overall survival in men with bone metastases from castration-resistant prostate cancer treated with bone-targeting radioisotopes: a meta-analysis of individual patient data from randomized clinical trials. JAMA Oncol (Internet). 2019;6:206-16.

43. Smart JG. The use of P32 IN the treatment of severe pain from bone metastases of carcinoma of the prostate. Br J Urol (Internet). 1965:37:139-47. 
44. Harrison MR, Wong TZ, Armstrong AJ, George DJ. Radium-223 chloride: a potential new treatment for castration-resistant prostate cancer patients with metastatic bone disease. Cancer Manag Res (Internet). 2013;5:1-14.

45. Sartor O. Isotope therapy for castrate-resistant prostate cancer: unique sequencing and combinations. Cancer J (Internet). 2020;22:342-6.

46. Porter AT, McEwan AJ, Powe JE, Reid R, McGowan DG, Lukka H, et al. Results of a randomized phase-III trial to evaluate the efficacy of strontium-89 adjuvant to local field external beam irradiation in the management of endocrine resistant metastatic prostate cancer. Int J Radiat Oncol Biol Phys (Internet). 1993;25:805-13.

47. Sartor O, Reid RH, Hoskin PJ, Quick DP, Ell PJ, Coleman RE, et al. Samarium153-Lexidronam complex for treatment of painful bone metastases in hormone-refractory prostate cancer. Urology (Internet). 2004;63:940-5.

48. Serafini AN, Houston SJ, Resche I, Quick DP, Grund FM, Ell PJ, et al. Palliation of pain associated with metastatic bone cancer using samarium-153 lexidronam: a double-blind placebo-controlled clinical trial. J Clin Oncol (Internet). 1998;16:1574-81.

49. Hoskin P, Sartor O, O'Sullivan JM, Johannessen DC, Helle SI, Logue J, et al. Efficacy and safety of radium-223 dichloride in patients with castrationresistant prostate cancer and symptomatic bone metastases, with or without previous docetaxel use: a prespecified subgroup analysis from the randomised, double-blind, phase 3 ALSYMPC. Lancet Oncol (Internet). 2014;15:1397-406.

50. Sartor O, Coleman R, Nilsson S, Heinrich D, Helle SI, O'Sullivan JM, et al. Effect of radium-223 dichloride on symptomatic skeletal events in patients with castration-resistant prostate cancer and bone metastases: results from a phase 3, double-blind, randomised trial. Lancet Oncol (Internet). 2014;15:738-46.

51. Parker C, Nilsson S, Heinrich D, Helle SI, O'Sullivan JM, Fossa SD, et al. Alpha emitter radium-223 and survival in metastatic prostate cancer. N Engl J Med (Internet). 2013;369:213-23.

52. Emmett L, Willowson K, Violet J, Shin J, Blanksby A, Lee J. Lutetium (177) PSMA radionuclide therapy for men with prostate cancer: a review of the current literature and discussion of practical aspects of therapy. J Med Radiat Sci (Internet). 2017;64:52-60.

53. Benesova M, Schafer M, Bauder-Wust U, Afshar-Oromieh A, Kratochwil C, Mier W, et al. Preclinical evaluation of a tailor-made DOTA-conjugated PSMA inhibitor with optimized linker moiety for imaging and endoradiotherapy of prostate cancer. J Nucl Med (Internet). 2015;56:914-20.

54. Kratochwil C, Giesel FL, Eder M, Afshar-Oromieh A, Benesova M, Mier W, et al. [(1)(7)(7)Lu]Lutetium-labelled PSMA ligand-induced remission in a patient with metastatic prostate cancer. Eur J Nucl Med Mol Imaging (Internet). 2015;42:987-8.

55. Iravani A, Violet J, Azad A, Hofman MS. Lutetium-177 prostate-specific membrane antigen (PSMA) theranostics: practical nuances and intricacies. Prostate Cancer Prostatic Dis (Internet). 2020;23:38-52.

56. Hofman MS, Violet J, Hicks RJ, Ferdinandus J, Thang SP, Akhurst T, et al. [(177)Lu]-PSMA-617 radionuclide treatment in patients with metastatic castration-resistant prostate cancer (LuPSMA trial): a single-centre, singlearm, phase 2 study. Lancet Oncol (Internet). 2018;19:825-33.

57. Violet J, Sandhu S, Iravani A, Ferdinandus J, Thang SP, Kong G, et al. Longterm follow-up and outcomes of retreatment in an expanded 50-patient single-center phase II prospective trial of (177)Lu-PSMA-617 theranostics in metastatic castration-resistant prostate cancer. J Nucl Med (Internet). 2020;61:857-65.

58. Paschalis A, Sheehan B, Riisnaes R, Rodrigues DN, Gurel B, Bertan C, et al. Prostate-specific membrane antigen heterogeneity and DNA repair defects in prostate cancer. Eur Urol (Internet). 2019;76:469-78.

59. Hofman MS, Emmett L, Sandhu SK, Iravani A, Joshua AM, Goh JC, et al. TheraP: A randomised phase II trial of 177Lu-PSMA-617 (LUPSMA) theranostic versus cabazitaxel in metastatic castration resistant prostate cancer (mCRPC) progressing after docetaxel: initial results (ANZUP protocol 1603). 2020;38:5500.

60. Rahbar K, Bodei L, Morris MJ. Is the vision of radioligand therapy for prostate cancer becoming a reality? An overview of the phase III VISION trial and its importance for the future of theranostics. J Nucl Med (Internet). 2019;60:1504-6.

61. Sartor AO, Morris MJ, Krause BJ. VISION: an international, prospective, open-label, multicenter, randomized phase 3 study of 177Lu-PSMA-617 in the treatment of patients with progressive PSMA-positive metastatic castration-resistant prostate cancer (mCRPC). 2019;37:TPS5099-TPS5099.
62. Atkins M. Immunotherapy combinations with checkpoint inhibitors in metastatic melanoma: current approaches and future directions. Semin Oncol (Internet). 2015;42(Suppl 3):S12-9.

63. Steven A, Fisher SA, Robinson BW. Immunotherapy for lung cancer. Respirology (Internet). 2016;21:821-33.

64. Donin NM, Lenis AT, Holden S, Drakaki A, Pantuck A, Belldegrun A, et al. Immunotherapy for the treatment of urothelial carcinoma. J Urol (Internet). 2017;197:14-22.

65. Kantoff PW, Higano CS, Shore ND, Berger ER, Small EJ, Penson DF, et al. Sipuleucel-T immunotherapy for castration-resistant prostate cancer. N Engl J Med (Internet). 2010;363:411-22.

66. Sartor O, Armstrong AJ, Ahaghotu C, McLeod DG, Cooperberg MR, Penson DF, et al. Survival of African-American and Caucasian men after sipuleucel-T immunotherapy: outcomes from the PROCEED registry. Prostate Cancer Prostatic Dis (Internet). 2020. https://doi.org/10.1038/ s41391-020-0213-7.

67. Gulley JL, Borre M, Vogelzang NJ, Ng S, Agarwal N, Parker CC, et al. Phase III trial of PROSTVAC in asymptomatic or minimally symptomatic metastatic castration-resistant prostate cancer. J Clin Oncol (Internet). 2019;37:1051-61.

68. Antonarakis ES, Eisenberger MA. Phase III trials with docetaxel-based combinations for metastatic castration-resistant prostate cancer: time to learn from past experiences. J Clin Oncol (Internet). 2013;31:1709-12.

69. Kwon ED, Drake CG, Scher HI, Fizazi K, Bossi A, van den Eertwegh AJ, et al. Ipilimumab versus placebo after radiotherapy in patients with metastatic castration-resistant prostate cancer that had progressed after docetaxel chemotherapy (CA184-043): a multicentre, randomised, double-blind, phase 3 trial. Lancet Oncol (Internet). 2014;15:700-12.

70. Beer TM, Kwon ED, Drake CG, Fizazi K, Logothetis C, Gravis G, et al. Randomized, double-blind, phase III trial of ipilimumab versus placebo in asymptomatic or minimally symptomatic patients with metastatic chemotherapy-naive castration-resistant prostate cancer. J Clin Oncol (Internet). 2017:35:40-7.

71. Vitkin N, Nersesian S, Siemens DR, Koti M. The tumor immune contexture of prostate cancer. Front Immunol (Internet). 2019;10:603.

72. Tucker MD, Zhu J, Marin D, Gupta RT, Gupta S, Berry WR, et al. Pembrolizumab in men with heavily treated metastatic castrate-resistant prostate cancer. Cancer Med (Internet). 2019;8:4644-55.

73. Antonarakis ES, Piulats JM, Gross-Goupil M, Goh J, Ojamaa K, Hoimes CJ, et al. Pembrolizumab for treatment-refractory metastatic castrationresistant prostate cancer: multicohort, open-label phase II KEYNOTE-199 study. J Clin Oncol (Internet). 2020;38:395-405.

74. Hoimes CJ, Graff JN, Tagawa ST, Hwang C, Kilari D, Ten Tije AJ, et al. KEYNOTE-199 cohorts (C) 4 and 5: phase II study of pembrolizumab (pembro) plus enzalutamide (enza) for enza-resistant metastatic castration-resistant prostate cancer (mCRPC). J Clin Oncol (Internet). 2020;2020:38.

75. Graff JN, Alumkal JJ, Drake CG, Thomas GV, Redmond WL, Farhad M, et al. Early evidence of anti-PD-1 activity in enzalutamide-resistant prostate cancer. Oncotarget (Internet). 2016;7:52810-7.

76. Yu EY, Piulats JM, Gravis G, Laguerre B, Arranz Arija JA, Oudard S, et al. KEYNOTE-365 cohort A updated results: Pembrolizumab (pembro) plus olaparib in docetaxel-pretreated patients (pts) with metastatic castration-resistant prostate cancer (mCRPC). J Clin Oncol (Internet). 2020;38:100-100

77. Yu EY, Park SH, Huang YH, Bennamoun M, Xu L, Kim J, et al. Phase III study of pembrolizumab (pembro) plus olaparib versus enzalutamide (enza) or abiraterone acetate (abi) in patients (pts) with metastatic castrationresistant prostate cancer (mCRPC) who progressed on chemotherapy: KEYLYNK-010. J Clin Oncol (Internet). 2020;38:TPS256-TPS256.

78. Petrylak DP, Shore ND, Bennamoun M, Ratta R, Piulats JM, Li B et al. Phase III study of pembrolizumab (pembro) plus docetaxel and prednisone for enzalutamide (enza)- or abiraterone acetate (abi)-pretreated patients (pts) with metastatic castration-resistant prostate cancer (mCRPC): KEYNOTE-921. J Clin Oncol (Internet) 2020;38:TPS262-TPS262.

79. Fizazi K, Gonzalez Mella P, Castellano D, Minatta JN, Rezazadeh Kalebasty A, Shaffer D, et al. Efficacy and safety of nivolumab in combination with docetaxel in men with metastatic castration-resistant prostate cancer in checkmate 9KD. Ann Oncol (Internet). 2019;30:v851-934.

80. Le DT, Durham JN, Smith KN, Wang H, Bartlett BR, Aulakh LK, et al. Mismatch repair deficiency predicts response of solid tumors to PD-1 blockade. Science (80-) (Internet) 2017;357:409-13. 
81. Marabelle A, Le DT, Ascierto PA, Di Giacomo AM, de Jesus-Acosta A, Delord JP, et al. Efficacy of pembrolizumab in patients with noncolorectal high microsatellite instability/ mismatch repair-deficient cancer: Results from the phase II KEYNOTE-158 study. J Clin Oncol (Internet). 2020;38:1-10.

82. Dawson NA, Zibelman M, Lindsay T, Feldman RA, Saul M, Gatalica Z, et al. An emerging landscape for canonical and actionable molecular alterations in primary and metastatic prostate cancer. Mol Cancer Ther (Internet). 2020;19:1373-82.

83. Abida W, Cheng ML, Armenia J, Middha S, Autio KA, Vargas HA, et al. Analysis of the prevalence of microsatellite instability in prostate cancer and response to immune checkpoint blockade. JAMA Oncol (Internet). 2019;5:471-8

84. Graham LS, Montgomery B, Cheng HH, Yu EY, Nelson PS, Pritchard $C$, et al. Mismatch repair deficiency in metastatic prostate cancer: response to PD-1 blockade and standard therapies. PLoS One (Internet). 2020;15:e0233260.

85. Wu YM, Cieślik M, Lonigro RJ, Vats P, Reimers MA, Cao X, et al. Inactivation of CDK12 delineates a distinct immunogenic class of advanced prostate cancer. Cell (Internet). 2018;173(1770-1782):e14.

86. Schweizer MT, Gulati R, Brown LC, McKay RR, Dorff TB, Kilari D, et al. CDK12-mutated prostate cancer (PC): clinical outcomes to standard therapies and immune checkpoint blockade. J Clin Oncol (Internet) 2020;4:382-92.

87. Antonarakis ES, Isaacsson Velho P, Fu W, Wang H, Agarwal N, Santos VS, et al. CDK12-altered prostate cancer: clinical features and therapeutic outcomes to standard systemic therapies, poly(ADP-Ribose) polymerase inhibitors, and PD-1 inhibitors. JCO Precis Oncol (Internet). 2020;4:370-81.

88. Matsumoto M, Takeda $Y$, Tatematsu M, Seya T. Toll-like receptor 3 signal in dendritic cells benefits cancer immunotherapy. Front Immunol (Internet). 2017;8:1897.
89. Ohta A, Gorelik E, Prasad SJ, Ronchese F, Lukashev D, Wong MK, et al. A2A adenosine receptor protects tumors from antitumor T cells. Proc Natl Acad Sci USA (Internet). 2006;103:13132-7.

90. Willingham SB, Ho PY, Hotson A, Hill C, Piccione EC, Hsieh J, et al. A2AR Antagonism with $\mathrm{CPI}-444$ induces antitumor responses and augments efficacy to anti-PD-(L)1 and anti-CTLA-4 in preclinical models. Cancer Immunol Res (Internet). 2018;6:1136-49.

91. Beshiri ML, Tice CM, Tran C, Nguyen HM, Sowalsky AG, Agarwal S, et al. A PDX/Organoid biobank of advanced prostate cancers captures genomic and phenotypic heterogeneity for disease modeling and therapeutic screening. Clin Cancer Res (Internet). 2018;24:4332-45.

92. Li Y, Liu Y, Xu H, Jiang G, Van der Jeught K, Fang Y, et al. Heterozygous deletion of chromosome $17 \mathrm{p}$ renders prostate cancer vulnerable to inhibition of RNA polymerase II. Nat Commun (Internet). 2018;9:4394.

93. Kounatidou E, Nakjang S, McCracken SRC, Dehm SM, Robson CN, Jones $D$, et al. A novel CRISPR-engineered prostate cancer cell line defines the AR- $V$ transcriptome and identifies PARP inhibitor sensitivities. Nucleic Acids Res (Internet). 2019:47:5634-47.

94. Frantzi M, Hupe MC, Merseburger AS, Schanstra JP, Mischak H, Latosinska A. Omics derived biomarkers and novel drug targets for improved intervention in advanced prostate cancer. Diagnostics (Internet). 2020;2020:10

\section{Publisher's Note}

Springer Nature remains neutral with regard to jurisdictional claims in published maps and institutional affiliations.
Ready to submit your research? Choose BMC and benefit from:

- fast, convenient online submission

- thorough peer review by experienced researchers in your field

- rapid publication on acceptance

- support for research data, including large and complex data types

- gold Open Access which fosters wider collaboration and increased citations

- maximum visibility for your research: over $100 \mathrm{M}$ website views per year

At BMC, research is always in progress.

Learn more biomedcentral.com/submissions 